\title{
Comparison of Development Indicators, According to Ages and Stages Questionnaires in Children with Pollakiuria Compared to Healthy
} Children

\author{
Parsa Yousefichaijan, ${ }^{1}$ Masoud Rezagholizamenjany, ${ }^{2,}$ Fatemeh Dorreh, ${ }^{3}$ Mohamad Rafiei, ${ }^{4}$ Hassan \\ Taherahmadi, ${ }^{5}$ Zahra Niyakan, ${ }^{2}$ and Ali Arjmand ${ }^{5}$ \\ ${ }^{1}$ Amir Kabir Hospital, Department of Pediatric Nephrology, Associate Professor of Pediatric Nephrology, Arak University of Medical Sciences, Arak, IR Iran \\ ${ }^{2}$ School of Medicine, Arak University of Medical Sciences, Arak, IR Iran \\ ${ }^{3}$ Department of Pediatric, Associate Professor of Pediatric, Arak University of Medical Sciences, Arak, IR Iran \\ ${ }^{4}$ Department of Biostatistics, Arak University of Medical Sciences, Arak, IR Iran \\ ${ }^{5}$ Department of Pediatric, Assistant Professor of Pediatric, Arak University of Medical Sciences, Arak, IR Iran \\ "Corresponding author: Masoud Rezagholizamenjany, School of Medicine, Arak University of Medical Sciences, Arak, IR Iran. Tel: +98-9184374727, E-mail: \\ masoudrezagholi074@gmail.com
}

Received 2017 January 22; Revised 2017 March 11; Accepted 2017 March 14.

\begin{abstract}
Background: Children with pollakiuria have extraordinary daytime urinary frequency, which means urination every 15 to 20 minutes per day, without nocturnal enuresis, urinary incontinence, dysuria, and UTIs. This can be associated with developmental disorders. Therefore, this study aimed at evaluating the effect of Pollakiuria on developmental disorders.

Methods: A total of 224 individuals were included in this study. The age range was 5 to 7 years old and 70 patients with Pollakiuria were allocated to the case group and 154 healthy individuals were included in the control group. Height, weight, and Body Mass Index (BMI) were measured and were compatible with gender and age. The following information was also recorded, personal and social development, problem solving, fine motor, gross motor, communication, defining words, understanding of contradictory words, counting numbers, names of colors, copying forms of $\square$ and $\Delta$, and walking on toes, which were obtained by the ages and stages questionnaires (ASQ) and nelson development table.

Results: From a total of 224 children, factor expressing growth and development condition in the case group was significantly less than the control group $(\mathrm{P}=0.001)$.

Conclusions: Development indicators, according to ages and stages questionnaires, in healthy children had a better status compared to children with Pollakiuria.
\end{abstract}

Keywords: Development Indicators, ASQ Questionnaire, Pollakiuria

\section{Background}

Bladder dysfunction, as a general term, describes abnormalities in either filling or emptying of the bladder (1-3). This condition, as a common problem in children, makes up more than $40 \%$ of pediatric urology clinic visits $(4,5)$. Children with Pollakiuria show extraordinary daytime urinary frequency, urination every 15 to 20 minutes per day without nocturnal enuresis, urinary incontinence, dysuria, and urinary tract infections (UTIs) (6).

This term is also used to define abnormally frequent small voids in a previously toilet trained child without evidence of polyuria or UTIs $(7,8)$.

In currently conducted surveys on young children, the most widely used parent completed questionnaires are ages and stages questionnaire (ASQ), which has high sensitivity and specificity for developmental delay detection (911). This approach has been used in non-standardized con- ditions, such as developmental screens and pediatric waiting rooms, despite validation of standardized conditions $(12,13)$. To identify behavioral or developmental disabilities in children, screening tests for developmental conditions have been used for decades (14). Detection of growth retardation was based on unstandardized physician knowledge and individual informal screening tests. This nonstandardized approach is generally unreliable. Use of clinical judgment alone by physicians detects less than $30 \%$ of developmental impairments in children $(15,16)$. Accordingly, this study aimed at evaluating development status in children with Pollakiuria based on the ASQ approach.

\section{Methods}

\subsection{Study Setting}

This research, as a hospital-based case-control study was conducted at a pediatric clinic of Amirkabir hospital. 


\subsection{Study Population}

A representative sample was taken from male and female students, aged 5 to 7 years of age with Pollakiuria. From a total of 224 children, 70 were selected as the case group and 154 as the control group.

\subsection{Measurements}

Study population in both groups with respect to demographic and socio-economic issues were at the same level. Height, weight, and BMI were measured. Also development of personal and socialconditions, problem solving, fine motor, gross motor, communication, defining words, understanding contradictory words, counting numbers, knowing the names of colors, copying forms of $\square$ and $\Delta$, and walking on toes were assessed by the ages and stages questionnaires (ASQ) and nelson development table.

\subsection{Ethical Considerations}

Ethical issues (including plagiarism, data fabrication, and double publication) were observed by the authors. In addition, the ethical committee of Arak University of Medical Sciences approved the study protocol.

\subsection{Statistical Analysis}

Data analysis was conducted by chi-square and $t$ test using the SPSS program and significance level of $\mathrm{P}<0.05$.

\subsection{Inclusion and Exclusion Criteria}

All children aged 5 to 7 years with Pollakiuria diagnosis were included in the study, yet children with systemic diseases, mental, and any other disorders that effect child development, as well as those with parents that did not provide their consent, were excluded.

\section{Results}

In total, 109 participants were male and 115 were female. Seventy patients with Pollakiuria were allocated to the case group (36 males (51.4\%) and 34 females (48.6\%)) and 154 healthy children were assigned to the control group (73 males (47.4\%) and 81 females (52.6\%)), which shows a nonsignificant difference and homogeneity of the 2 groups ( $\mathrm{P}$ $=0.6$ ).

Personal-social index was positive in $47.1 \%$ of case and $87 \%$ of controls. Problem solving was positive in $52.9 \%$ of cases and $83.1 \%$ of controls. Fine motor was positive in $47.1 \%$ of cases and $64.7 \%$ of controls. Gross motor was positive in $55.7 \%$ of case and $88.3 \%$ of controls. Communication was positive in $48.6 \%$ of cases and $87 \%$ of controls. Knowing the name of colors was positive in $44.3 \%$ of cases and $6.5 \%$ of controls. Ability to wear clothes was positive in $58.6 \%$ of cases and $11 \%$ of controls. Understanding the meaning of words was positive in $54.3 \%$ of cases and $13.6 \%$ of controls. Use of complex words was positive in $44.3 \%$ of cases and $19.5 \%$ of controls. Definition of words was positive in $55.7 \%$ of cases and $2.6 \%$ of controls. Understanding opposite words was positive in $61.4 \%$ of cases and $2.6 \%$ of controls. Number Counting was positive in $51.4 \%$ of cases and $6.5 \%$ of controls. Whole man drags was positive in $44.3 \%$ of cases and $18.8 \%$ of controls. Copying $\square$ was positive in $61.4 \%$ of cases and $11.7 \%$ of controls. Copying $\Delta$ was positive in $52.9 \%$ of cases and $23.4 \%$ of controls. Walk on toes was positive in $57.1 \%$ of cases and $1.9 \%$ of controls. Capers was positive in $52.9 \%$ of cases and $1.9 \%$ of controls. Regarding father's education, $11.4 \%$ of cases and $23.4 \%$ of controls had fathers with a diploma degree, and $57.2 \%$ of cases and $52.6 \%$ of controls had fathers with higher than diploma degree. In addition, regarding mother's education, $30 \%$ of cases and $20.1 \%$ of controls had a diploma degree, and $18.6 \%$ of cases and $50.2 \%$ of controls had mothers higher than a diploma degree. There was a statistically significant difference between the 2 groups $(\mathrm{P}=0.001)$ (Table 1$)$.

\section{Discussion}

Pollakiuria, known as extraordinary daytime urinary frequency, has many psychiatric and developmental complications. The results showed lower growth and development status in children with Pollakiuria. The first description of Pollakiuria was provided by Asnes and Mones in 1973 using radiological studies (17). Stephens and colleagues reported on the same disease as dummy syndrome and identified psychological factors as the principal cause of this disorder (18). Basar and colleagues in a study showed that $30 \%$ of children with tethered spinal cord had Pollakiuria (19). Male dominance in Pollakiuria was seen in some studies leading to externalization of male genitalia (20-22), however, in the current study, there was an equal number of boys and girls. In some studies, certain medications, such as milnacipran and fluoxetine, may result in Pollakiuria $(23,24)$. Nevertheless, the patients in this study were not exposed to these medications. In a series by Chan and colleagues, spontaneous resolution of Pollakiuria in all 48, 3.9- to 7.8-year-old, patients had occurred, within 12 days to 5 months after diagnosis (25); this has also been reported by other studies (26-28). Wang and colleagues conducted a study to evaluate Pollakiuria in Tic Disorders (TD), they concluded that TD occurs in children with Pollakiuria, yet it is not frequently encountered (17). Also, in a study by Vilijakainen and colleagues, they observed that vitamin D could improve the growth and development status of children (29). In addition, Robert and colleagues conducted 
another study on the correlation of socioeconomic and development status in children; in this study, they observed that family characteristics, children's own characteristics, and external support systems could effect developmental status (30). The limitation of this study was the small size of patients in the 2 groups and lack of cooperation by certain patients and their parents. However, according to these reasons, further studies, especially prospective researches with greater sample size will be needed in the future to evaluate the correlation of Pollakiuria with growth and developmental disorders.

\subsection{Conclusions}

Development indicators in healthy children, according to ages and stages questionnaires, have better status compared to children with Pollakiuria. Based on this, growth and developmental disorders could be reduced by treatment of Pollakiuria in children.

\section{Acknowledgments}

This work was performed in partial fulfillment of the requirements for a PhD degree by Dr. Zahra Niyakan, school of medicine, Arak University of Medical Sciences, Arak, Iran.

\section{Footnote}

Conflicts of Interest: The authors declare no competing interests.

\section{References}

1. Duel BP, Steinberg-Epstein R, Hill M, Lerner M. A survey of voiding dysfunction in children with attention deficit-hyperactivity disorder. $J$ Urol. 2003;170(4 Pt 2):1521-3. doi: 10.1097/01.ju.0000091219.46560.7b. [PubMed: 14501650] discussion 1523-4.

2. Farhat W, Bagli DJ, Capolicchio G, O'Reilly S, Merguerian PA, Khoury A, et al. The dysfunctional voiding scoring system: quantitative standardization of dysfunctional voiding symptoms in children. J Urol. 2000;164(3 Pt 2):1011-5. [PubMed: 10958730].

3. Yousefichaijan P, Rezagholizamenjany M, Rafiei F, Taherahmadi $\mathrm{H}$, Rafiei M. The Relationship between Blood Biomarkers Level and the Prognosis of Nephrotic Syndrome in the Children. Int J Pediatr. 2016;4(9):3489-97.

4. Hellerstein S, Linebarger JS. Voiding dysfunction in pediatric patients. Clin Pediatr (Phila). 2003;42(1):43-9. doi: 10.1177/000992280304200107. [PubMed: 12635981].

5. Rezagholizamenjany M, Yousefichaijan P. An overview on peritoneal dialysis. Ann Res Dialysis. 2016;1(1).

6. Itoh K, Nishi T. Post marketing surveillance of propiverine hydrochloride (BUP-4 tablets $®)$ in pollakiuria and urinary incontinence. Japanese Pharmaco Ther. 2002;30(12):1023-36.

7. Tsushimi T, Yagi T, Tomozawa N, Ohnishi H. Retroperitoneal solitary fibrous tumor of the pelvis with pollakiuria: a case report. BMC Res Notes. 2012;5:593. doi: 10.1186/1756-0500-5-593. [PubMed: 23107063].
8. Ismael SS, Epstein T, Bayle B, Denys P, Amarenco G. Bladder cooling reflex in patients with multiple sclerosis. J Urol. 2000;164(4):1280-4. [PubMed: 10992381].

9. Byrne DG, Davenport SC, Mazanov J. Profiles of adolescent stress: the development of the adolescent stress questionnaire (ASQ). J Adolesc. 2007;30(3):393-416. doi: 10.1016/j.adolescence.2006.04.004. [PubMed: 16750846].

10. Yu LM, Hey E, Doyle LW, Farrell B, Spark P, Altman DG, et al. Evaluation of the Ages and Stages Questionnaires in identifying children with neurosensory disability in the Magpie Trial follow-up study. Acta Paediatr. 2007;96(12):1803-8. doi: 10.1111/j.1651-2227.2007.00517.x. [PubMed: 17971191].

11. Skellern CY, Rogers Y, O'Callaghan MJ. A parent-completed developmental questionnaire: follow up of ex-premature infants. J Paediatr Child Health. 2001;37(2):125-9. [PubMed: 11328465].

12. Piek JP, Dawson L, Smith LM, Gasson N. The role of early fine and gross motor development on later motor and cognitive ability. Hum Mov Sci. 2008;27(5):668-81. doi: 10.1016/j.humov.2007.11.002. [PubMed: 18242747].

13. Yousefichaijan P, Dorreh F, Shariatmadari F, Ghandi Y, Alinejad S, Kahbazi M, et al. Serum Vitamin D Status in reflux nephropathy. Scholars J Appl Med Sci. 2016;4(12):4325-7.

14. Zhang JX, Miao XX, Guo GL. Development status of backfilling technology using raw waste in coal mining. J Mining Safety Engin. 2009;4:002.

15. Gollenberg AL, Lynch CD, Jackson LW, McGuinness BM, Msall ME. Concurrent validity of the parent-completed Ages and Stages Questionnaires, 2nd Ed. with the Bayley Scales of Infant Development II in a low-risk sample. Child Care Health Dev. 2010;36(4):485-90. doi: 10.1111/j.1365-2214.2009.01041.x. [PubMed: 20030657].

16. Ambrosini PJ. Historical development and present status of the schedule for affective disorders and schizophrenia for school-age children (K-SADS). J Am Acad Child Adolesc Psychiatry. 2000;39(1):4958. doi: 10.1097/00004583-200001000-00016. [PubMed: 10638067].

17. Wang HS, Chang HL, Chang SW. Pollakiuria in children with tic disorders. Chang Gung Med J. 2005;28(11):773-8. [PubMed: 16422183].

18. Stephens FD, Whitaker J, Hewstone AS. True, false and sham urinary tract infections in children. Med J Aust. 1966;2(18):840-2. [PubMed: 5928302].

19. Basar H, Aydoganli L, Yuksel M, Basar M, Akdemir G, Kaptanoglu E. The outcome of urological findings in operated tethered cord patients. Int Urol Nephrol. 1997;29(2):167-71. [PubMed: 9241543].

20. Cohen DJ, Leckman JF, Pauls D. Neuropsychiatric disorders of childhood: Tourette's syndrome as a model. Acta Paediatr Suppl. 1997;422:106-11. [PubMed: 9298805].

21. Carter LL, Leckman JF, Scahill L, McDougle CJ, Leckman JF, Cohen DJ. Tourette's Syndrome: tics, obsessions, compulsions, developmental psychopathology and clinical care. ; 1999.

22. Wang HS. Tourette syndrome: not just a tic disorder. Chang Gung Med J. 2005;28(8):527-9. [PubMed: 16265842].

23. Sancho A, Martinez-Mir I, Palop V. Pollakiuria and micturition syndrome related to fluoxetine. Medicina Clinica. 1995;105(15):598-9.

24. Regina W, Vandel P, Vandel S, Sechter D, Bizouard P. Clinical tolerance of a new antidepressant-milnacipran. L'Encephale. 1998;25(3):252-8.

25. Chen WF, Huang SC. Pollakiuria: extraordinary daytime urinary frequency a common problem in pediatric practice. Chang Gung Med J Chang Gung Memorial Hospital. 1995;18(2):115-9.

26. Cohen HA, Nussinovitch M, Kauschansky A, Straussberg R, Ashkenasi A, Frydman M, et al. Extraordinary daytime urinary frequency in children. J Fam Pract. 1993;37(1):28-9. [PubMed: 8345336].

27. Watemberg N, Shalev H. Daytime urinary frequency in children. Clin Pediatr (Phila). 1994;33(1):50-3. doi: 10.1177/000992289403300109. [PubMed: 8156728].

28. Brock J3. The frequency and frequency dysuria syndromes of childhood: hypercalciuria as a possible etiology. Urology. 1994;44(3):411-2. [PubMed: 8073556]. 
29. Viljakainen HT, Korhonen T, Hytinantti T, Laitinen EK, Andersson S, Makitie O, et al. Maternal vitamin D status affects bone growth in early childhood-a prospective cohort study. Osteoporos Int. 2011;22(3):88391. doi: 10.1007/s00198-010-1499-4. [PubMed: 21153404].
30. Bradley RH, Corwyn RF. Socioeconomic status and child development. Annu Rev Psychol. 2002;53:371-99. doi: 10.1146/annurev.psych.53.100901.135233. [PubMed: 11752490]. 
Table 1. Age and Development Indicators of Primary Mono-symptomatic Nocturnal Enuresis Cases $(n=53)$ and Controls $(n=57)^{a}$

\begin{tabular}{|c|c|c|c|}
\hline Variables & Case Group & Control Group & PValue $^{\text {b }}$ \\
\hline Gender & & & 0.6 \\
\hline Male & $36(51.4)$ & $73(47.4)$ & \\
\hline Female & $34(48.6)$ & $81(52.6)$ & \\
\hline Person - Social Index & & & 0.001 \\
\hline$<31.5(-)$ & $37(52.9)$ & $20(13.0)$ & \\
\hline$>31.5(+)$ & $33(47.1)$ & $134(87)$ & \\
\hline Problem Solving & & & 0.001 \\
\hline$<30.5(-)$ & $33(47.1)$ & $26(16.9)$ & \\
\hline$>30.5(+)$ & $37(52.9)$ & $128(83.1)$ & \\
\hline Fine Motor & & & 0.001 \\
\hline$<30.5(-)$ & $37(52.9)$ & $42(27.3)$ & \\
\hline$>30.5(+)$ & $33(47.1)$ & $145(64.7)$ & \\
\hline Gross Motor & & & 0.001 \\
\hline$<32.7(-)$ & $31(44.3)$ & $18(11.7)$ & \\
\hline$>32.7(+)$ & $39(55.7)$ & $136(88.3)$ & \\
\hline Communication & & & 0.001 \\
\hline$<31.7(-)$ & $36(51.4)$ & $20(13)$ & \\
\hline$>31.7(+)$ & $34(48.6)$ & $134(87)$ & \\
\hline Knowing Name of Colors & & & 0.001 \\
\hline Yes & $39(55.7)$ & $144(93.5)$ & \\
\hline No & $31(44.3)$ & $10(6.5)$ & \\
\hline Wearing one's own clothes & & & 0.001 \\
\hline Yes & $29(41.4)$ & $137(89.0)$ & \\
\hline No & $41(58.6)$ & $17(11)$ & \\
\hline Understanding of words & & & 0.001 \\
\hline Complete & $32(45.7)$ & $133(86.4)$ & \\
\hline Incomplete & $38(54.3)$ & $21(13.6)$ & \\
\hline Use of Complex Words & & & 0.001 \\
\hline Complete & $39(55.7)$ & $124(80.5)$ & \\
\hline Incomplete & $31(44.3)$ & $30(19.5)$ & \\
\hline Words Definition & & & 0.001 \\
\hline Complete & $31(44.3)$ & $150(97.4)$ & \\
\hline Incomplete & $39(55.7)$ & $4(2.6)$ & \\
\hline Understanding Opposite Words & & & 0.001 \\
\hline Complete & $27(38.6)$ & $150(97.4)$ & \\
\hline Incomplete & $43(61.4)$ & $4(2.6)$ & \\
\hline Counting Numbers & & & 0.001 \\
\hline Yes & $34(48.6)$ & $144(93.5)$ & \\
\hline No & $36(51.4)$ & $10(6.5)$ & \\
\hline
\end{tabular}




\begin{tabular}{|c|c|c|c|}
\hline Whole Man Drag & & & 0.001 \\
\hline Yes & $39(55.7)$ & $125(81.2)$ & \\
\hline No & $31(44.3)$ & $29(18.8)$ & \\
\hline Copy $\square$ & & & 0.001 \\
\hline Yes & $27(38.6)$ & $136(88.3)$ & \\
\hline No & $43(61.4)$ & $18(11.7)$ & \\
\hline Copy $\Delta$ & & & 0.001 \\
\hline Yes & $33(47.1)$ & $118(76.6)$ & \\
\hline No & $37(52.9)$ & $36(23.4)$ & \\
\hline Walk on Toes & & & 0.001 \\
\hline Yes & $30(42.9)$ & $151(98.1)$ & \\
\hline No & $40(57.1)$ & $3(1.9)$ & \\
\hline Caper & & & 0.001 \\
\hline Yes & $33(47.1)$ & $151(98.1)$ & \\
\hline No & $37(52.9)$ & $3(1.9)$ & \\
\hline Father's Education & & & 0.001 \\
\hline Under Diploma & $8(11.4)$ & $36(23.4)$ & \\
\hline Diploma & $22(31.4)$ & $37(24.0)$ & \\
\hline Associate & $22(31.4)$ & $26(16.9)$ & \\
\hline Bachelor & $18(25.8)$ & $55(35.7)$ & \\
\hline Mother's Education & & & 0.001 \\
\hline Under Diploma & $21(30.0)$ & $31(20.1)$ & \\
\hline Diploma & $36(51.4)$ & $43(27.9)$ & \\
\hline Associate & $11(15.7)$ & $31(20.2)$ & \\
\hline Bachelor & $2(2.9)$ & $49(31.8)$ & \\
\hline Economical Status, Million IRR & & & 0.001 \\
\hline$<1$ & 0 & $64(41.6)$ & \\
\hline$>1$ & $70(100.0)$ & $90(58.4)$ & \\
\hline BMI & & & 0.001 \\
\hline$<0$ & $4(5.7)$ & $1(0.6)$ & \\
\hline $5-10$ & $23(32.9)$ & $21(13.6)$ & \\
\hline $10-25$ & $19(27.1)$ & $14(9.1)$ & \\
\hline $25-50$ & $11(15.7)$ & $25(16.2)$ & \\
\hline $50-75$ & $9(12.9)$ & $41(26.6)$ & \\
\hline $75-85$ & $3(4.3)$ & $25(16.2)$ & \\
\hline $85-90$ & $1(1.4)$ & $22(14.3)$ & \\
\hline $90-90$ & 0 & $5(3.2)$ & \\
\hline Weight Percentile & & & 0.001 \\
\hline$<3$ & $10(14.3)$ & 0 & \\
\hline $3-15$ & $30(42.5)$ & $3(1.9)$ & \\
\hline $15-50$ & $21(30.0)$ & $60(39.0)$ & \\
\hline $50-85$ & $8(11.4)$ & $72(46.8)$ & \\
\hline $85-97$ & $1(1.4)$ & $19(12.3)$ & \\
\hline
\end{tabular}


Height Percentile

\begin{tabular}{|c|c|c|c|}
\hline$<3$ & $10(14.3)$ & 0 & \\
\hline $3-15$ & $34(48.6)$ & $12(7.8)$ & \\
\hline $15-50$ & $17(24.3)$ & $66(42.9)$ & \\
\hline $50-85$ & $9(12.9)$ & $48(31.2)$ & \\
\hline $85-97$ & 0 & $28(18.2)$ & \\
\hline Family Status & & & 0.3 \\
\hline Presence of Parents & $63(90)$ & $144(93.5)$ & \\
\hline Father Only & $5(7.1)$ & $7(4.6)$ & \\
\hline Mother Only & $2(2.9)$ & $3(1.9)$ & \\
\hline
\end{tabular}

Abbreviations: +, as inappropriate; -, as appropriate.

${ }^{\mathrm{a}}$ The values are presented as No. (\%).

${ }^{\mathrm{b}} \mathrm{P}$ values $<0.5$ were considered statistically significant. 